\title{
STUDY OF SOIL AMPLIFICATION BASED ON MICROTREMOR AND SEISMIC RECORDS IN LIMA PERU
}

\author{
Diana CALDERON ${ }^{1}$, Toru SEKIGUCHI ${ }^{2}$, Shoichi NAKAI ${ }^{3}$, Zenon AGUILAR $^{4}$, Fernando
} LAZARES $^{5}$

\footnotetext{
${ }^{1}$ Member of JAEE, PhD. Candidate, Department of Urban Environment Systems, Chiba University, Chiba, Japan, diana_c@graduate.chiba-u.jp

${ }^{2}$ Member of JAEE, Assistant Professor, Department of Urban Environment Systems, Chiba University, Chiba, Japan, tsekiguc@faculty.chiba-u.jp

${ }^{3}$ Member of JAEE, Professor, Department of Urban Environment Systems, Chiba University, Chiba, Japan, nakai@ faculty.chiba-u.jp

${ }^{4}$ Professor, Faculty of Civil Engineering, National University of Engineering, Lima, Peru, zaguilar@uni.edu.pe

${ }^{5}$ Professor, Faculty of Civil Engineering, National University of Engineering, Lima, Peru, flazares@uni.edu.pe
}

\begin{abstract}
The dynamic characteristics of the ground in Lima, capital of Peru, specifically the amplification are investigated. By using the small and large microtremor array measurements we estimated the soil velocity profiles with depths to the bedrock in many cases. These profiles were used to estimate the amplification factors. Important results are the large amplification factors at EMO, VSV, CAL and CMA (La Molina, Villa El Salvador, El Callao and Bellavista district, respectively).
\end{abstract}

Key Words: Dispersion curve, Shear-wave velocity profile, Transfer function, Amplification factor, Site effect

\section{INTRODUCTION}

Lima, capital of Peru, is situated in the central-west side of the South American continent, bordered by the Pacific Ocean in a zone of high seismic activity known as the Ring of Fire. Earthquakes in this area are originated mainly due to the subduction of the Nazca Plate under the South American plate.

Lima has a long history of being hit by destructive earthquakes that have caused building damage and human losses. According to Silgado (1978), the largest earthquake reported in the capital occurred in October 28, 1746, with a magnitude $M_{W}$ of 8.4; the most destructive earthquake occurred in May 24, 1940 with a magnitude $M_{W}$ of 8.2, and the last large earthquake occurred in October 3, 1974 with a magnitude $M_{W}$ of 6.1 .

Since earthquake engineering in Peru developed during the last decades, most of the studies of Lima's earthquakes are for the October 17 1966, May 311970 and October 3, 1974 events.

From the last earthquakes we know the places where damage are prone to occur, districts like 
Callao, La Punta, Chorrillos and La Molina, reported large amplifications. However, we cannot restrict the damage-prone areas to these places because from the time the last earthquake occurred up to now Lima have experienced a large urbanization process; and areas that were not populated in the past are now urbanized; districts like Villa El Salvador and Ventanilla are the typical examples (Fig. 1 shows the locations of these districts) Therefore, a comprehensive study of Lima's soil dynamic characteristics will help to prevent future damage caused by earthquakes.

During 2003 and 2005, Cismid, the Japan-Peru Center for Earthquake Engineering Research and Disaster Mitigation that belongs to the National University of Engineering, conducted a seismic microzonation study in Lima. The study was based on geotechnical boring data analysis, consideration of geological aspects (Fig. 1), and one-point microtremor measurements; important results of this study were soil distribution maps (Fig. 2), predominant period distribution maps (Fig.3) and zonation maps.

Although this microzonation study is up to now the most complete in Lima, it has some limitations such as the very shallow depth of the boring data, and the lack of seismic methods to estimate deep soil profiles, the ones that are necessary to conduct quantitatively dynamic analyses. In consequence, the results of that study should be taken as preliminaries.

On the other hand, the study presented here, aims to evaluate the dynamic characteristics, specifically the amplification levels and their corresponding periods of vibration, at various sites of Lima that represent the different soil conditions in the city. For that purpose, we have estimated soil structures with depths extending to the bedrock by conducting array measurements. In addition, we have evaluated the site-effects in CAL and CSM (Fig. 2) by using seismic records. It is important to note here that there was no previous information in Lima about the deep soil structures and consequently this study intends to provide a first approximation of the deep soil structure in the city.

It is worth to mention that this study is part of the project:"Enhancement of Earthquake and Tsunami Disaster Mitigation Technology in Peru", which started in 2010; and which is sponsored by the Japan Science and Technology Agency (JST) and Japan International Cooperation Agency (JICA) under the framework of "Science and Technology Research Partnership for Sustainable Development"(SATREPS).

\section{GEOLOGICAL AND GEOMORFOLOGICAL ASPECTS}

The geomorphology of Lima can be subdivided into the Andes Cordillera, coastal plain, coastal headlands and Holocene alluvial floodplain.

The Andes Cordillera is the place where the Rimac River has its origin; the river drops from about $4800 \mathrm{~m}$ in height to sea level over a distance of only $120 \mathrm{~km}$. The coastal plain is the area between the Andes and the Pacific Ocean. The coastal headlands represent the highest relief along the coast. Finally the Holocene floodplain includes areas historically affected by recurrent floods along the present-day river valleys (le Roux et al 2000).

The geology of Lima region reflects the subduction of the Nazca Plate under the South American Plate and consequent uplift and volcanic activity. (Karakouzian et al 1997).

The Quaternary deposits consist of alluvial, marine and eolian materials. Their distribution is wide, especially for the alluvial deposits. It is not erroneous to say that the majority of the metropolitan area is built over the alluvial deposit that was originated by the Chillon and Rimac rivers that eroded, transported and deposited the sediments in their course.

The composition of these deposits is heterogeneous and does not follow a vertical nor horizontal reasonable system. The reason for this heterogeneity is the superposition of various alluvial fans, the variable distances from the apex to the deposit; the different discharge regimens of the two rivers, the capacity of variable transport (seasonal and during important weather changes); and the variations on the sea level. The alluvial deposits consist of gravels, with boulders of $20 \mathrm{~cm}$ in the center of the city and of $60 \mathrm{~cm}$ in the east. The sand as well as the silt-clay material creates lenses within the gravels. Occasionally, isolated areas of organic soils of more than two meters depth appears. In the coastal cliff the poor horizontal stratification of the debris in the form of lenses cut by the sea erosion can be observed. 


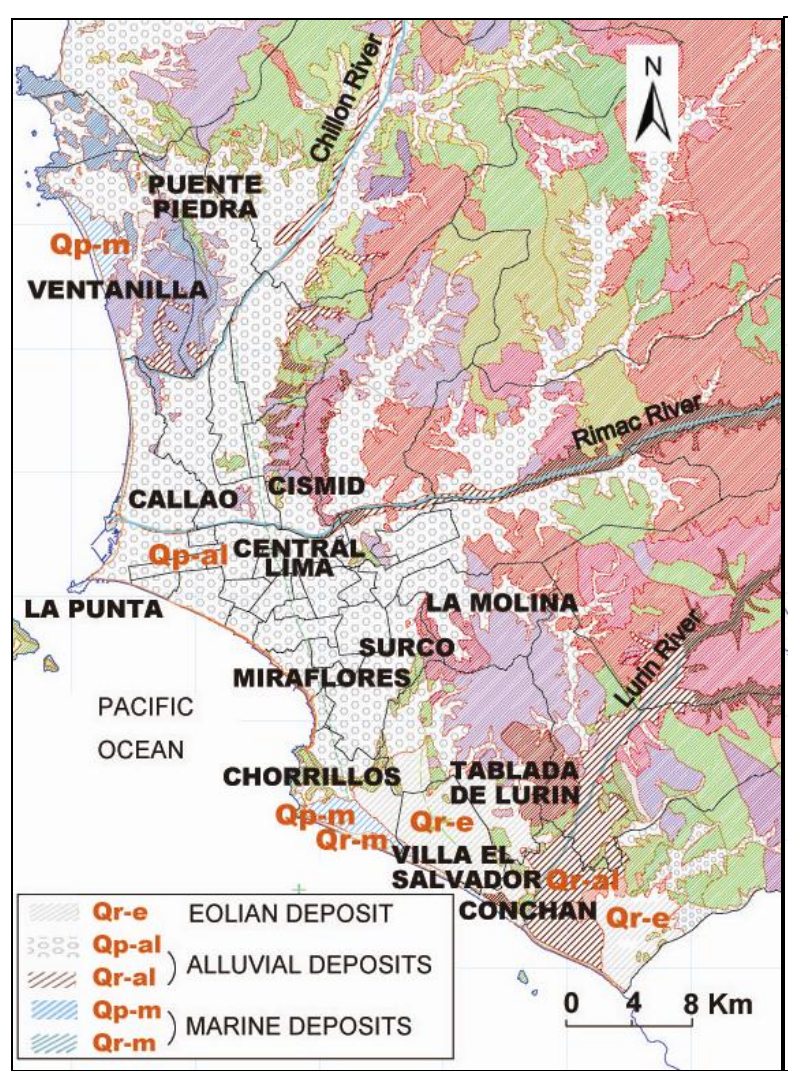

Fig. 1 Geological Map (INGEMMET 1992 and Martinez Vargas 1995)

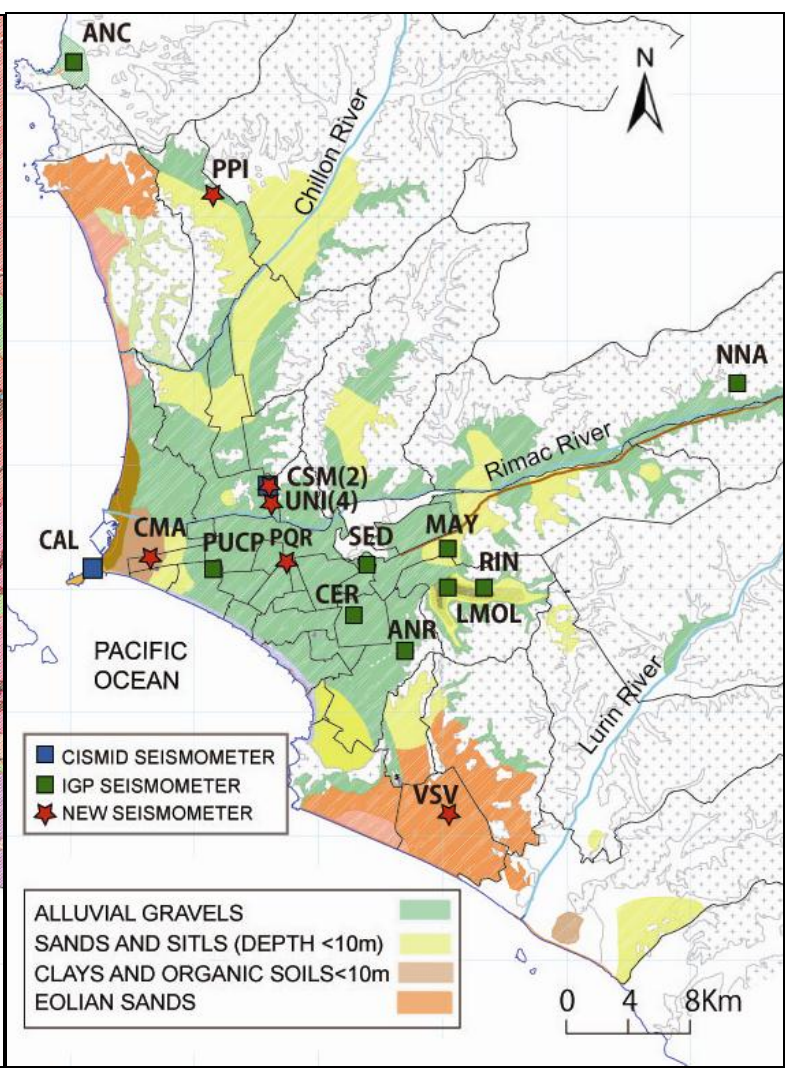

Fig. 2 Seismometers in Lima city over the soil distribution map (Cismid 2005)

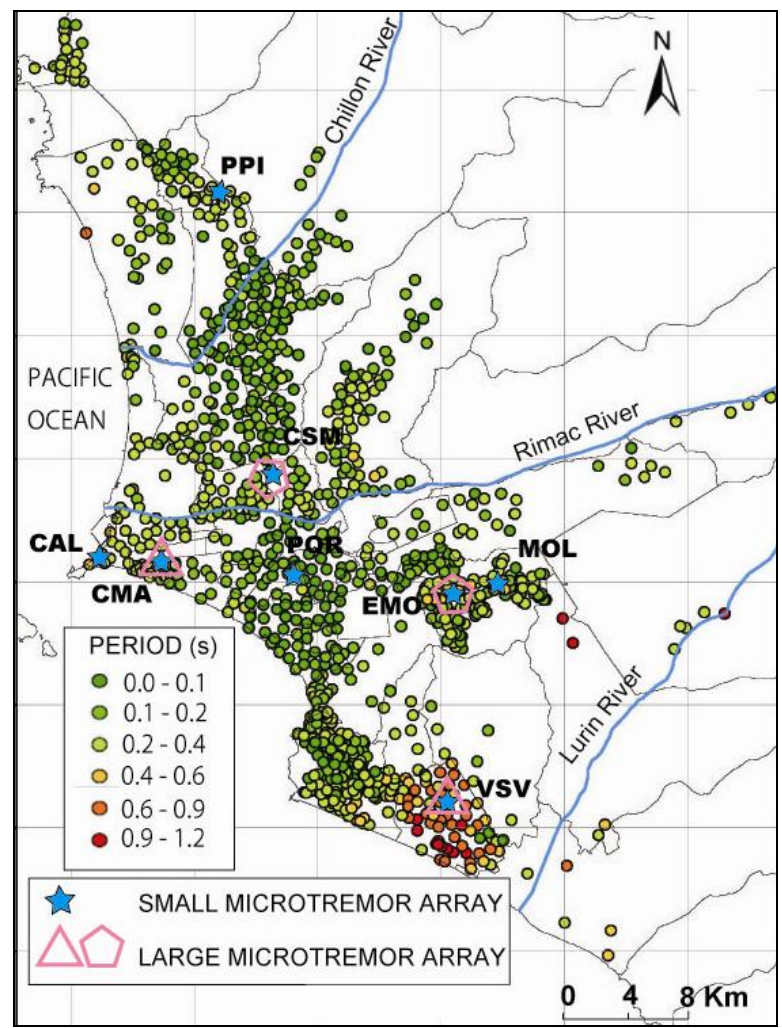

Fig. 3 Location of microtremor arrays over the predominant period distribution map calculated from the H/V spectrum from single-point microtremor measurements (Cismid 2005, Cismid 2010) 
From the literature, the geology of the area under study can be summarized as:

1. The sediments of the Chillon River are fine and the gravels are from volcanic origins; on the other hand, the sediments of the Rimac River have their origins in granite and granodiorite.

2. The alluvial material becomes clayey with depth.

3. At the southeast limit of the cliff (Chorrillos), the sandy debris predominates.

4. At Callao the silt-sands deposits are predominant.

The depth of the alluvial deposits can be expected to be from 400 to $600 \mathrm{~m}$ for the area of the alluvial cone of the Chillon River; and the depth of the alluvial deposit from the Rimac River is about 200m.

Besides the alluvial deposits, there are also marine deposits. These are relatively new-sand deposits, originated by the erosive actions of the ocean's waves and currents. Their main placement is in the beaches of Villa, Conchan, Chorrillos and La Punta (Fig. 1), also appearing along the coastal line due to fluctuating sea levels during the Pleistocene era. It is expected that there exist the deposition of marine sediments, particularly, sands, silts and clays, interlayered with the alluvional products. Furthermore, the more recent eolian deposits are generally found in the areas of the alluvial cones of the Rimac and Chillon, in particular in Tablada de Lurin, on the right side of the Chillon River, the southwest side of the San Lorenzo island and in a number of zones around the Surco and La Molina basin, some of which, due to their small size, do not appear on the geological map (Cismid 2005).

\section{ARRAY MEASUREMENTS}

In order to estimate the soil profile characteristics, such as the shear-wave velocity and the thickness of each layer constituting the soil profile, active and passive surface wave measurements were conducted.

The measurement campaigns were conducted at eight sites, in which small arrays were measured. Large arrays were measured at four of the eight sites. The assumption is made here, that an array with radius over fifty meters is considered a large array. In Fig. 3 the spatial location of these arrays is shown; and in Table 1 a list indicating the size of the arrays at each measured site is presented.

The location of the arrays was selected based on the soil classification map (Fig. 2), the H/V spectrum's peak-period map (Fig. 3); and the reports on the most damaged areas from large earthquakes. Special attention was given to places with soft soils and long period of vibration; hence, places like EMO, MOL (both in La Molina district), CAL, CMA (El Callao and Bellavista district respectively), and VSV (Villa El Salvador) were selected. On the other hand, places with stiff soils were also selected in order to compare the effect of different soil profiles in the vibration characteristics.

In each site, the small arrays consist of two linear arrays of 0.5 and $2 \mathrm{~m}$ sensor distance and circular arrays of 10, 20, and 45m radius; in the linear arrays the surface wave was generated by an artificial source (active measurement), while in the circular arrays the natural ambient vibration (microtremor) was recorded (passive measurement). The large array consisted of circular arrays of 100, 200,500 and $1000 \mathrm{~m}$ radius. In almost all the arrays six sensors were used except in CMA and in VSV array where four sensors were used. Table 2 shows the details of the measurement characteristics. The sampling frequency and the low-pass filter values shown in this table were chosen depending on the array size and the target surface-wave wavelength. The sampling point for each array measurement varies from 4000 to 12000 points and was chosen based on the array dimension and the expected period range.

\section{Implementation of microtremor sensors}

Two types of microtremor sensors were introduced to Peru through this project. One is the moving-coil velocimeter CR 4.5-1S, whose natural period is one second, with logger GEODAS 15HS manufactured by Anet Co., Ltd., and that was used to measure small size arrays with radius smaller than $50 \mathrm{~m}$ because of the limited size of the cables that connect the sensors with the logger. 
The other is the servo velocimeter CV-374-AV2 manufactured by Tokyo Sokushin Co., Ltd., with a frequency range from 0.1 to $100 \mathrm{~Hz}$. These sensors were used for large array measurements since they can be synchronized by GPS devices and no hard-wiring is required to conduct the measurements.

Table 1 Array sizes in each of the eight measured places, and the type of analysis performed to obtain the dispersion curve.

\begin{tabular}{|c|c|c|c|c|c|c|c|c|c|c|}
\hline \multirow{3}{*}{$\begin{array}{l}\text { Obs. } \\
\text { Place } \\
\text { ID }\end{array}$} & \multicolumn{10}{|c|}{ Array Dimensions } \\
\hline & \multicolumn{2}{|c|}{$\begin{array}{c}\text { Linear } \\
\text { (sensor distance } \\
\text { in meters) }\end{array}$} & \multicolumn{8}{|c|}{$\begin{array}{c}\text { Circular } \\
\text { (Radius in meters) }\end{array}$} \\
\hline & 0.5 & 2.0 & 6.0 & $10 \sim 15$ & $18 \sim 30$ & $40 \sim 45$ & 100 & 200 & $400 \sim 500$ & $900 \sim 1000$ \\
\hline PPI & & $\bigcirc$ & & $\bigcirc$ & $\bigcirc \boldsymbol{\Delta}$ & & & & & \\
\hline CAL & 0 & $\bigcirc$ & 0 & O & $\bigcirc \boldsymbol{\Delta}$ & & & & & \\
\hline PQR & 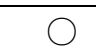 & $\mathrm{O}$ & & O & $\bigcirc \boldsymbol{\Delta}$ & $\bigcirc \boldsymbol{\Delta}$ & & & & \\
\hline MOL & $\bigcirc$ & $\mathrm{O}$ & & $\bigcirc \boldsymbol{\Delta}$ & O & O & & & & \\
\hline EMO & O & O & & $\bigcirc \boldsymbol{A}$ & $\bigcirc \boldsymbol{\Delta}$ & $\bigcirc \boldsymbol{\Delta}$ & $\square$ & $\square$ & $\square$ & \\
\hline VSV & O & $\mathrm{O}$ & & $\bigcirc \boldsymbol{\Delta}$ & $\bigcirc \boldsymbol{\Delta}$ & $\bigcirc \boldsymbol{\Delta}$ & & & & $\square$ \\
\hline CMA & $\bigcirc$ & O & & $\mathrm{O}$ & $\bigcirc \boldsymbol{\Delta}$ & $\bigcirc$ & $\square$ & & $\square$ & $\square$ \\
\hline CSM & $\bigcirc$ & $\bigcirc$ & & $\bigcirc \boldsymbol{\Delta}$ & $\bigcirc \boldsymbol{\Delta}$ & $\bigcirc \boldsymbol{\Delta}$ & & & & \\
\hline
\end{tabular}

: F-k spectrum analysis (Small Array using hard-wiring)

$\square$ : F-k spectrum analysis (Large Array using GPS)

\ : noise-compensated Circular Array analysis (Small Array using hard-wiring)

Table 2 Array measurement characteristics

\begin{tabular}{|l|c|c|c|c|}
\hline & \multicolumn{4}{|c|}{ Array Dimension } \\
\cline { 2 - 5 } & $\begin{array}{c}\text { Linear } \\
\text { (sensor } \\
\text { distance) }\end{array}$ & \multicolumn{3}{|c|}{$\begin{array}{c}\text { Circular } \\
\text { (Radius) }\end{array}$} \\
\cline { 2 - 5 } & $0.5 \sim 2.0 \mathrm{~m}$ & $10 \sim 20 \mathrm{~m}$ & $30 \sim 45 \mathrm{~m}$ & $90 \sim 1000 \mathrm{~m}$ \\
\hline Sampling frequency (Hz) & $1000 \sim 2000$ & $500 \sim 1000$ & $200 \sim 500$ & 200 \\
\hline Low-pass filter (Hz) & 300 & $100 \sim 300$ & $25 \sim 100$ & - \\
\hline Sampling time (min.) & 10 & 10 & 10 & $20 \sim 40$ \\
\hline Gain (dB) & 60 & 60 & 60 & 60 \\
\hline Number of stacking & 50 & $20 \sim 30$ & $20 \sim 30$ & $20 \sim 30$ \\
\hline
\end{tabular}

\section{SEISMOMETER NETWORKS}

\section{Current Seismometer Networks}

Currently, Cismid has two seismometers in operation in Lima, one in station CSM and another in station CAL (Fig. 2). In addition to this network the Geophysical Institute of Peru (IGP) manages ten seismometers, which make a total of twelve seismometers distributed over Lima city.

\section{Implementation of New Seismometers}

The small number of seismometers is a limitation for a comprehensive study of the dynamic 
characteristics of the soils in Lima.

In order to overcome this limitation, SATREPS provided Cismid with ten new seismometers CV-374-A2 that measure accelerations, with a frequency range from $\mathrm{DC}$ to $100 \mathrm{~Hz}$, produced by Tokyo Sokushin Co., Ltd. To date, eight have already been installed, while the remaining two will be installed in the near future. The distribution of the installed seismometers is shown in Fig. 2.

Among the new seismometers installed, four were placed at the National University Campus forming an array of seismometers (UNI). One was located in Cismid (CSM) where an old seismometer is also in operation. The remaining three are distributed at the north (PPI station), south (VSV station), and central part of Lima (PQR station).

With these new seismometers in Lima we will have a total of twenty two seismometers.

\section{DISPERSION CURVES}

The high resolution F-k spectrum analysis (Capon 1969) together with SPAC analysis (Aki, 1957) are the most popular methods to calculate the dispersion curve of Rayleigh waves; there is another method called the Centerless Circular Array analysis (CCA) (Cho et al 2004) that is an extension of the SPAC analysis and that has proved to be robust in the calculation of this curve. These analyses base their theory on the correlation between the vertical recordings of the sensors that structure the array.

The vertical recordings of microtremors are analyzed because it is considered that this component contains mainly Rayleigh waves.

In this study we have applied the F-k and the nc-CCA analyses for the calculation of the dispersion curves. The nc-CCA analysis (where nc stands for noise compensated) is a method to correct for phase velocity underestimations due to noise that could happen when applying the CCA analysis (Cho et al 2007, 2010).

During the procedure of the F-k analysis, F-k spectra are evaluated before plotting the dispersion curve. These spectra indicate the direction toward the main source and the phase velocity values for each frequency. In Fig. 4, F-k spectra for two arbitrary frequencies, chosen from the low and high frequency range of the dispersion curve (Fig. 5), are shown for each site, since eight sites were measured, sixteen F-k spectra are presented.

From this Figure, the majority of the spectra show one prominent peak, however, in some cases as in Fig. 4 (a) there is more than one peak indicating that waves come from different directions possibly due to the complex underground structure.

\section{Observed dispersion curves}

Fig. 5 shows the dispersion curves obtained from the array measurements, these are called observed dispersion curves. In this figure we can observe that dispersion curves at EMO, VSV, CMA and CSM reach values of velocities of about $3000 \mathrm{~m} / \mathrm{s}$. For the eolian sand deposit found at VSV and the clay and organic soil deposit at CMA, large arrays were fundamental to reach that velocity of $3000 \mathrm{~m} / \mathrm{s}$, but in EMO and CSM, where alluvial gravel deposits were found, small arrays were enough to reach that velocity. This fact suggests that the depth to the bedrock in EMO and CSM is shallower than in VSV and CMA.

Unlike the conventional methods of dispersion curve calculation (such as the F-k spectrum analysis) that measure velocities at a wavelength of about two or three times the sensor distance, the nc-CCA analysis allows us to measure the velocities at a longer wavelength range of about three to five times the sensor distance (Cho et al, 2004 ). The effect of this long wavelength measurement can be observed in the dispersion curves shown in Fig. 5, when comparing the F-k and nc-CCA method of analysis for the same array size. The F-k analysis calculates values of phase velocities for shorter periods than the nc-CCA analysis.

Another characteristic of the observed dispersion curves is the continuity of the points that form them, which were calculated from different arrays size. There are, however, cases in which discontinuity was observed, such as in the range of long periods in the VSV and CMA dispersion curve (Fig. 5(f) and (g)); this problem will be discussed more extensively in the next section. 

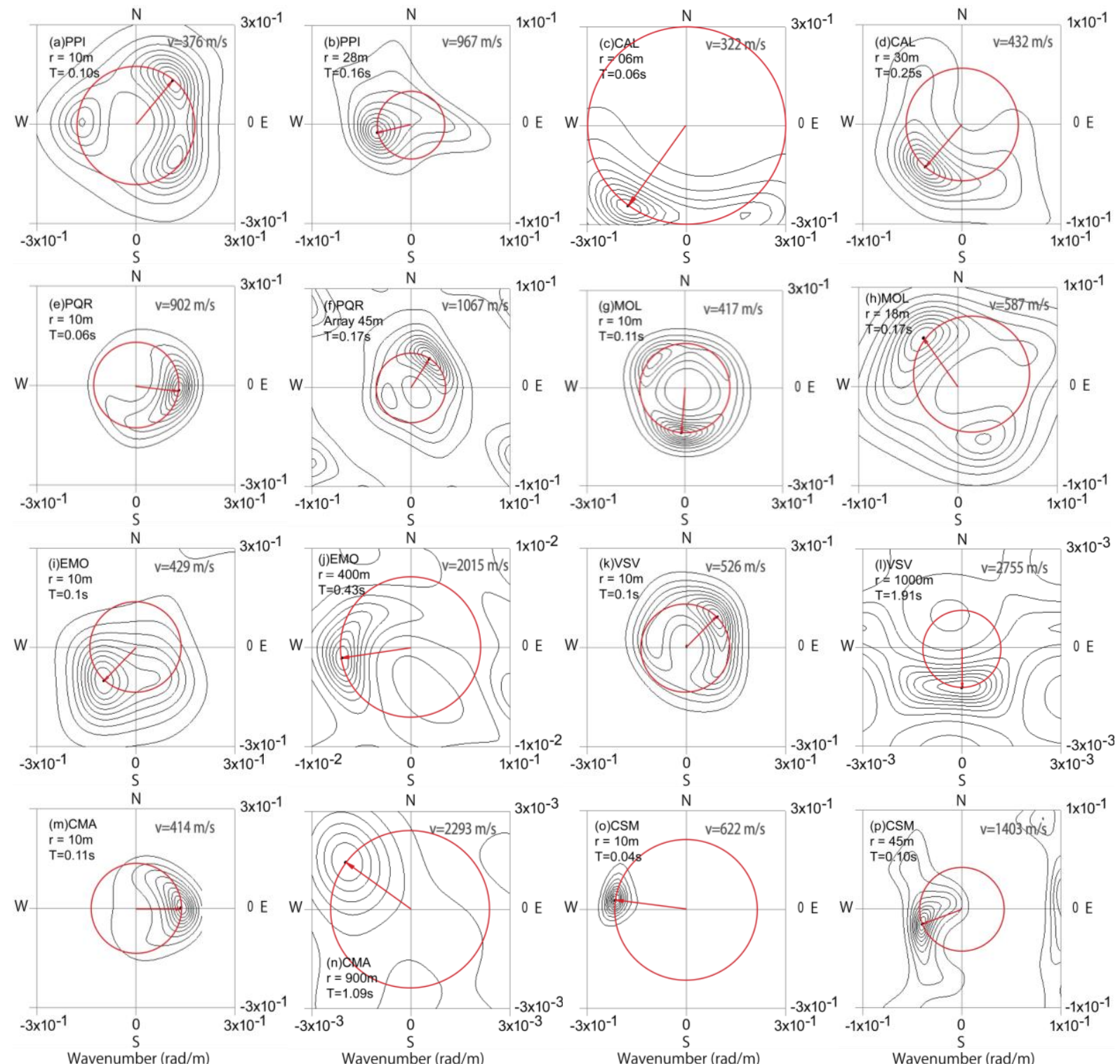

Fig. 4 F-k Spectra for each of the measured places

In some cases an inverse behavior is found such as in Fig. 5 (c), (e) and (g), this may be reflecting the effect of higher modes.

\section{Range of periods of low wave power}

From the observed dispersion curves at VSV and CMA in Fig. 5(f) and (g) there is a range of periods in which the phase velocity dispersion curve is not continuous. In Fig. 6 we are analyzing the cause of this discontinuity. In this figure we are showing the dispersion curve (a), the Fourier spectrum (b) and the coherence spectrum (c) at VSV site, the coherence was calculated between the central sensor and sensors on the circle forming the array of $200 \mathrm{~m}$ radius.

In the dispersion curve we can observe that in the range from 0.5 to 1.5 seconds the curve does not show any value (Fig. 6 (a)), which could be related to the low power of the Fourier spectrum in this period range (Fig. 6 (b)); and to the small values of coherence Fig. 6 (c), in fact, the coherence starts to decrease in this range of period and is high for longer periods. 

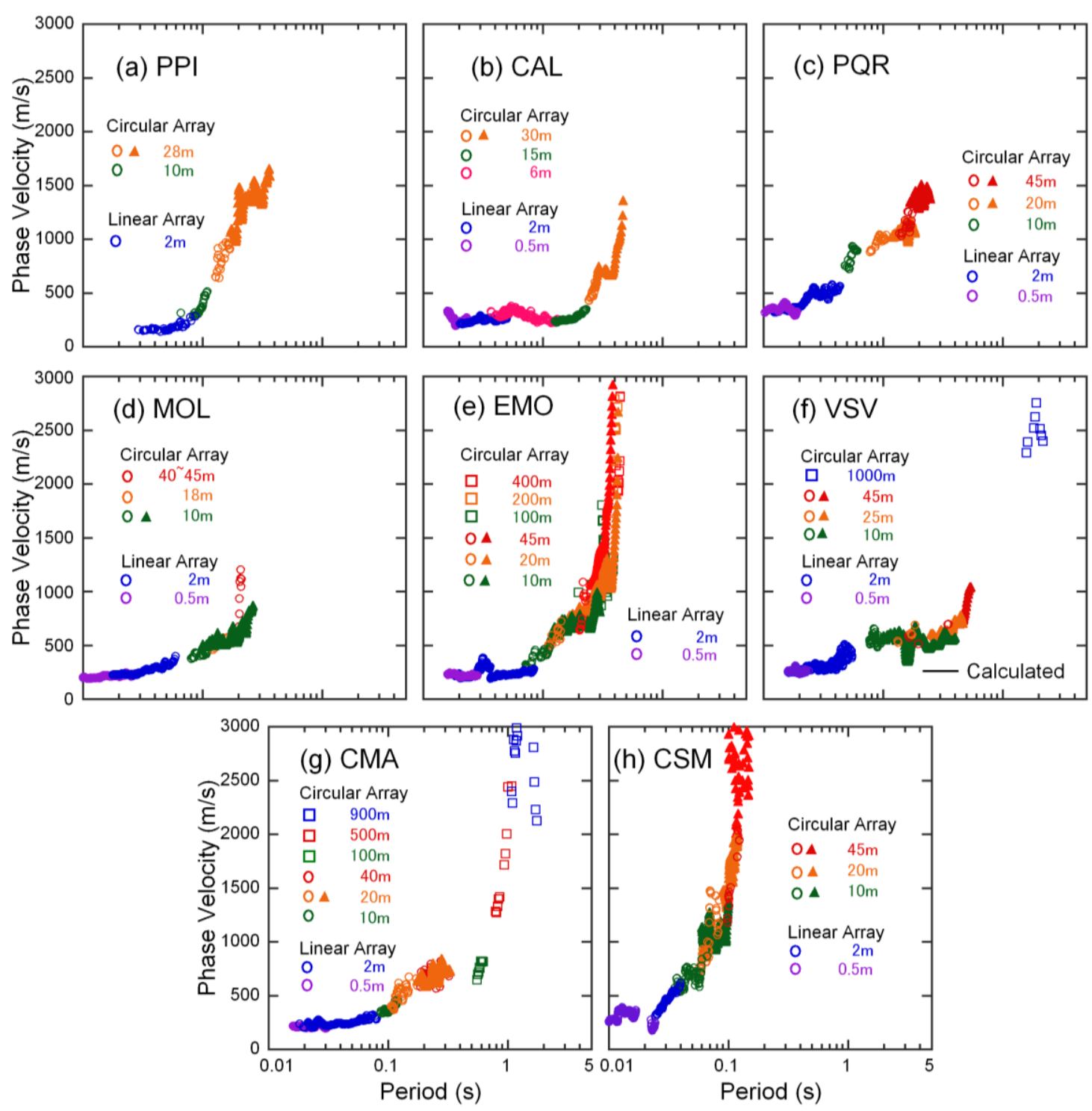

O F-k Analysis (Small Array)

F-k Analysis (Large Array)

nc-CCA Analysis

Fig. 5 Observed Dispersion Curves
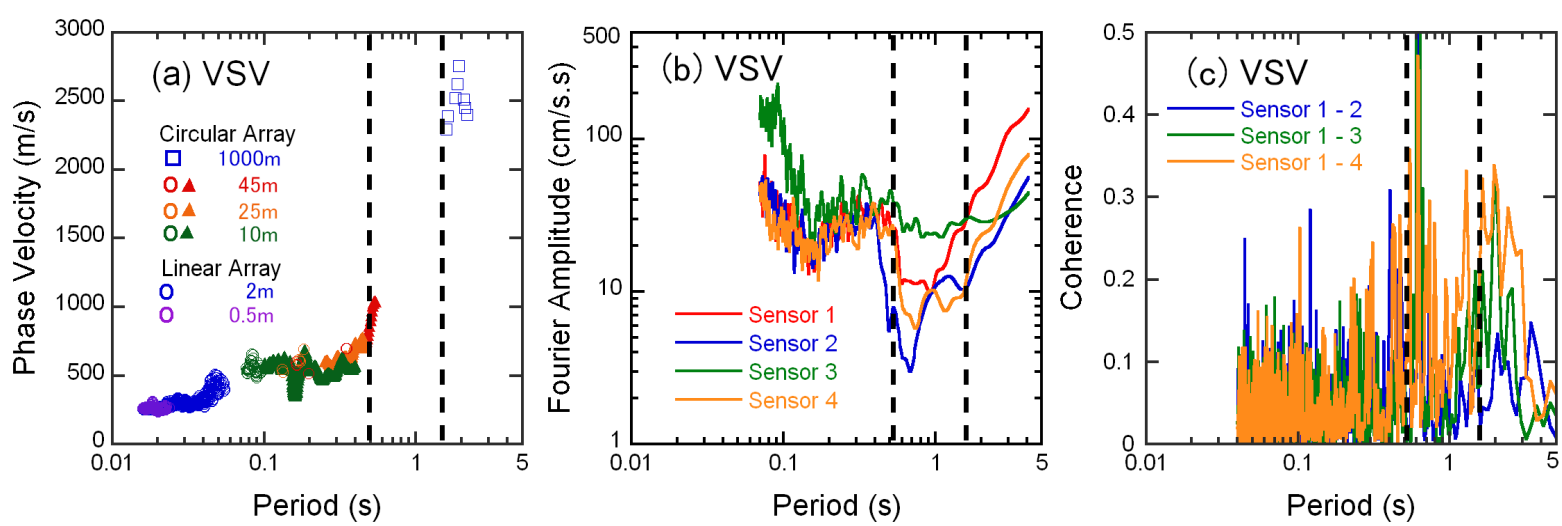

Fig. 6 (a) Observed phase velocity dispersion curve, (b) Fourier Spectrum and (c) Coherence spectrum for the circular array of 200m radius at VSV. Sensor 1, 2, 3, and 4 are the sensors forming the array. 


\section{ESTIMATED PROFILES}

The dispersion curves of Rayleigh waves are inverted in order to estimate the shear-wave velocity profiles. This process is carried out through different methods, such as the conventional least square method and the genetic algorithm (GA) method, lately the GA method has been widely used because it has proved to be a good technique to estimate velocity profiles; and therefore, we have adopted this method in our study.

As input data the GA method requires the number of layers and an initial model which consists of a range of shear wave velocity and thickness for each layer (Table 3), this model was determined based on shallow soil profiles obtained by other exploration methods. In the process of the inversion the $\mathrm{P}$ wave velocity and the density values are necessary to calculate the dispersion curve, we have adopted values of density from 1700 to $2200 \mathrm{~kg} / \mathrm{m}^{3}$ depending on the soil type; for the $V_{p}$ (P wave velocity) values we have used the formula proposed by Kitsunezaki (1990); this formula relates $V_{s}$ values with $V_{p}$ and as shown in equation (1) and (2).

$$
\begin{array}{lll}
V_{p}=\left(1.29+1.11 * V_{s}\right) & V_{s}<=2.07 & (\mathrm{~km} / \mathrm{s}) \\
V_{p}=1.732 * V_{s} & V_{s}>2.07 & (\mathrm{~km} / \mathrm{s})
\end{array}
$$

We have used this formula even though it was proposed for Japan, due to the scarce information of $V_{p}$ and density values in Peru.

Table 3 Boundary matrix for the Genetic Algorithm Inversion Analysis

\begin{tabular}{|l|l|l|}
\hline \multicolumn{3}{|c|}{ PPI } \\
\hline Layer & \multicolumn{1}{|c|}{ Vs (m/s) } & Thickness(m) \\
\hline 1 & {$[100-200]$} & {$[1-10]$} \\
\hline 2 & {$[300-700]$} & {$[10-40]$} \\
\hline 3 & {$[700-1000]$} & {$[10-30]$} \\
\hline 4 & {$[1000-1500]$} & - \\
\hline \multicolumn{3}{|c|}{ CAL } \\
\hline 1 & {$[200-300]$} & {$[1-5]$} \\
\hline 2 & {$[350-450]$} & {$[1-5]$} \\
\hline 3 & {$[200-400]$} & {$[10-40]$} \\
\hline 4 & {$[500-1000]$} & {$[20-50]$} \\
\hline 5 & {$[1000-1500]$} & - \\
\hline \multicolumn{3}{|c|}{ PQR } \\
\hline 1 & {$[300-400]$} & {$[1-5]$} \\
\hline 2 & {$[500-600]$} & {$[1-10]$} \\
\hline 3 & {$[700-900]$} & {$[25-50]$} \\
\hline 4 & {$[1100-1250]$} & {$[40-50]$} \\
\hline 5 & {$[1250-1750]$} & - \\
\hline \multicolumn{3}{|c|}{ MOL } \\
\hline 1 & {$[200-300]$} & {$[1-5]$} \\
\hline 2 & {$[300-450]$} & {$[5-15]$} \\
\hline 3 & {$[400-500]$} & {$[5-20]$} \\
\hline 4 & {$[500-700]$} & {$[15-35]$} \\
\hline 5 & {$[700-1000]$} & - \\
\hline
\end{tabular}

\begin{tabular}{|l|l|l|}
\hline \multicolumn{3}{|c|}{ EMO } \\
\hline Layer & \multicolumn{1}{|c|}{ Vs (m/s) } & Thickness(m) \\
\hline 1 & {$[200-300]$} & {$[5-10]$} \\
\hline 2 & {$[500-600]$} & {$[30-40]$} \\
\hline 3 & {$[750-900]$} & {$[50-80]$} \\
\hline 4 & {$[1400-1700]$} & {$[100-200]$} \\
\hline 5 & {$[2000-3250]$} & - \\
\hline \multicolumn{3}{|c|}{ VSV } \\
\hline 1 & {$[200-300]$} & {$[1-10]$} \\
\hline 2 & {$[400-600]$} & {$[50-100]$} \\
\hline 3 & {$[700-1000]$} & {$[50-150]$} \\
\hline 4 & {$[1400-1800]$} & {$[300-450]$} \\
\hline 5 & {$[3000-3500]$} & - \\
\hline \multicolumn{3}{|c|}{ CMA } \\
\hline 1 & {$[200-220]$} & {$[5-10]$} \\
\hline 2 & {$[450-1000]$} & {$[80-150]$} \\
\hline 3 & {$[1000-1500]$} & {$[50-100]$} \\
\hline 4 & {$[1500-2000]$} & {$[300-500]$} \\
\hline 5 & {$[2000-2500]$} & {$[200-300]$} \\
\hline 6 & {$[2500-3000]$} & - \\
\hline \multicolumn{3}{|c|}{ CSM } \\
\hline 1 & {$[350-400]$} & {$[2-7]$} \\
\hline 2 & {$[650-750]$} & {$[10-20]$} \\
\hline 3 & {$[1300-1800]$} & {$[20-50]$} \\
\hline 4 & {$[2000-2500]$} & {$[40-55]$} \\
\hline 5 & {$[2500-3000]$} & - \\
\hline \multicolumn{3}{|c|}{} \\
\hline 5
\end{tabular}


In this study the number of layers adopted was from four to six, and the initial models were chosen in some cases based on available boring data and shear-wave velocity profiles that were estimated by the surface wave method called the Multichannel Analysis of Surface waves (MASW) (Park 1999). The number of generations and number of populations for the inversion process was from twenty to fifty. We have considered the effect of higher modes in the inversion process since the dispersion curve showed an inversely dispersive trend (Tokimatsu 1995).

For the inversion analysis a target dispersion curve is required, for that reason, we have selected the most representative points of the observed dispersion curve shown in Fig. 5 and called them the target points in Fig. 7.

Based on the target dispersion curves we have estimated the shear-wave velocity profiles shown in Fig 8. The inversion process was carried out several times due to the non-uniqueness of the solution related to this process, and a total of five inverted profiles were estimated.

In Fig. 7, we can observe a good agreement between the target points and the calculated dispersion curves; and that in general, the five calculated curves for each site are very similar, which supports the solutions of the inversion process. Additionally, in this figure the medium responses of the inverted profiles are shown, they indicate that the fundamental mode is prevailing in most of the period range of the dispersion curves; however there are some range of periods in which higher modes are prevailing, these ranges coincide with the inversed shape of the dispersion curves or with the large values of phase velocities in the dispersion curve.

As another way to verify the inverted profiles we have calculated their $\mathrm{H} / \mathrm{V}$ spectra for the fundamental mode and compared them with the $\mathrm{H} / \mathrm{V}$ spectra observed from horizontal and vertical components at the same place. Observed spectra were smoothed by a Parzen window with $0.2 \mathrm{~Hz}$ bandwidth (Fig. 9). From this Figure we can observe that the calculated H/V spectra are in a fairly good agreement with the observed ones, suggesting that the inverted profiles are reasonably reliable.

We can also observe that the peak periods in the calculated H/V spectra at VSV and EMO tend to give periods larger than the observed ones. At CAL the observed spectrum shows two peaks, but the calculated spectrum shows only one, possibly because the lack of the larger peak reflects the fact that the depth of the estimated profile there is very shallow and it is not enough to produce a larger peak.

It is also worth to mention that the calculated H/V spectrum at PQR does not produce a sharp peak, which is consistent with the observed spectrum. A discussion to the estimated profile at each place is presented below. For depth to the bedrock we understand the depth at which the shear velocity is about $3000 \mathrm{~m} / \mathrm{s}$.

\section{Estimated Profile at PPI (Puente Piedra district)}

This district is located in the northern part of Lima city; according to the microzonation study (Cismid 2005) at shallow depths the sediments are from loose to dense fine sands, silty clays and landfills. In other parts there is a gravelly material composed of medium dense poorly-graded gravels with clays and silts. Underlying these materials there are poorly-graded sands of medium to loose compactness. According to the zonation map most of the urban area of the district is in the most competent zone from the seismic and geotechnical point of view. It is important to point out that the previous microzonation study at this place was made based on shallow soil exploration data.

The estimated shear-wave velocity profile found from the inversion analysis is shown in Fig 8 (a). The maximum size of the arrays was a circle of $28 \mathrm{~m}$ radius. Based on the shear-wave velocity profile and the boring data near PPI a description of the soils is attempted. There is a shallow layer of about $5 \mathrm{~m}$ with soils of low velocity that can be regarded as loose sands, underlying this soil until about $60 \mathrm{~m}$ the soil velocity increases to values that may account for dense sand, down to $60 \mathrm{~m}$ the soil velocity may correspond to a dense gravel deposit.

\section{Estimated Profile at CAL (The El Callao district)}

This place is located in the border between the El Callao district and the La Punta district.

The geological formation at this place is particular because the shallow materials have been taken 
by the sea from the cliffs located in the southern districts of Miraflores and Chorrillos (Huaman et al 1991). The soil profile here consists of a poorly-graded gravel layer overlying a dense sand deposit until about $15 \mathrm{~m}$. Under this layer there is a fine sand deposit with silts and clays, organic clayey silt, and stiff high plasticity clays with about $20 \mathrm{~m}$ thickness. Finally, there is a dense sandy gravel deposit (Cismid 2005).

According to the micozonation study of this area (Cismid 2005) CAL is located at zone 4, which is characterized as the less competent soils that show high amplification and long period of vibration.

The estimated shear-wave velocity profile is shown in Fig. 8 (b). Based on this profile and boring data near CAL, we observe that at few meter depth there is a change of velocities from large to low values that may be caused by the heterogeneous conformation of the deposit, underlying there is a layer with velocities that may account for stiff clays or silts until $35 \mathrm{~m}$ depth, the last layer estimated with the arrays shows a velocity value that is coherent with the dense gravel mentioned in the literature.

\section{Estimated Profile at PQR (Lima district)}

Lima district is at the center of the Lima Metropolitan area. Stratigraphically the alluvial deposit covers most of the city soils and it is expected that the thickness to the base rock here be about $200 \mathrm{~m}$ (Cismid 2005). The soil profile consists of a very shallow layer (about $1 \mathrm{~m}$ ) of silts that overlay the conglomerate of the Rimac River. This conglomerate is medium dense at shallow depths and increases its compactness with the depth. Based on the shear-wave velocity profile shown in Fig. 8 (c), there is a shallow layer of less than $5 \mathrm{~m}$ that may correspond to silt deposits, after this the soil velocity increases gradually until $100 \mathrm{~m}$, that is the maximum depth of the estimated profile, the velocity values until this depth may account for the conglomerate.

\section{Estimated Profile at MOL (The La Molina district)}

MOL is one of the two places measured in the La Molina district. It is located in front of the district Municipality.

The land surface of the district is heterogeneous, varying from outcrops in the slope of the hills to colluvial soils in the lowlands near the hills; and large fluvial-alluvial deposits in the plains of the valley at large distances from the hills. There are also areas covered by eluvial materials, specifically eolian sands deposited in large amounts in the depressions and on the hillsides. These heterogeneous materials make the stratigraphy of the area to be very variable (Cismid 2010(b)).

According to the microzonation study (Cismid 2010(b)) MOL is in the zone II that corresponds to colluvial gravel soils and poorly-graded sand layers of moderate thickness. The estimated shear-wave velocity profile is shown in Fig. 8 (d). We can observe that the velocities increase gradually until about $30 \mathrm{~m}$ depth; from this depth to about $60 \mathrm{~m}$ (maximum estimated depth) there is a significant change in the velocity value, which can be due to the presence of a very dense gravel deposit.

\section{Estimated Profile at EMO (National Agrarian University Campus)}

EMO is the second place of measurement in the La Molina district. It is located inside the campus of the National Agrarian University.

The shear-wave velocity profile estimated is shown in Fig. 8 (e), we can observe that the gradual increase of the velocity until approximately $100 \mathrm{~m}$. From this depth there is a thick deposit with a relatively large value of velocity of very dense gravels until it reaches the bedrock at the depth of about $200 \mathrm{~m}$.

From the microzonation study of this district (Cismid 2010(b)) four seismic zones are identified in the Campus; it means that there is high variability of the soils; therefore, an averaged estimated profile may fail to characterize a unique point of the array at large depths. 

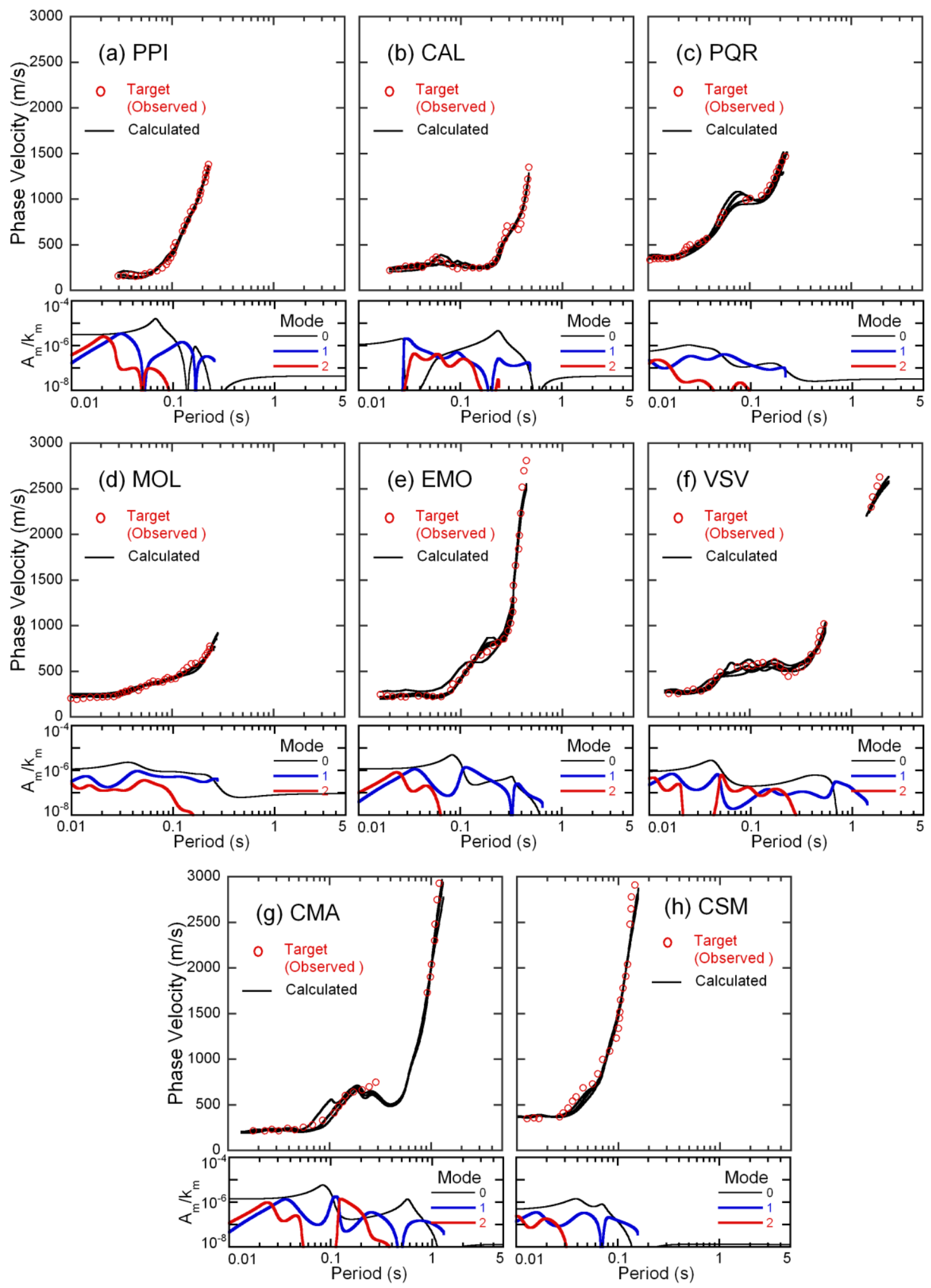

Fig. 7 Observed target, Calculated Dispersion Curves and Medium Responses 


\section{Estimated Profile at VSV (Villa El Salvador district)}

This district is located in the south of Lima, and consists of a coastal border composed by eolian sea deposits; plain areas covered by gravel and eolian sands transported from the Lurin River and from the beaches nearby; and a hill called Lomo de Corvina composed of eolian sands, transported during the Pleistocene epoch by winds from the adjacent beach (Cismid 2010(a)).

Lithostratigraphic units that outcrop in the hill Lomo de Corvina and surroundings consists of sedimentary rocks of the early cretaceous epoch represented by the Pamplona formation, sea deposits and eolian deposits of the quaternary period (Cismid 2010(a)).

According to the microzonation study in (Cismid 2010(a)), the area of study belongs to zone III, and consists of loose eolian sand deposits of large depths and sea deposits. The shallow layer consists of landfill until $2 \mathrm{~m}$ depth, underlying this material there is a very thick poorly-graded medium to fine sand of loose compactness that increases with the depth.

Fig. 8 (f) is the shear-wave velocity profile, from here we observe that there is a low velocity for the very few meters, this velocity accounts for a shallow soft sand deposit. From 10m to 200m depth the velocity increases gradually; with values that are characteristics of a very dense sand. Finally just above the bedrock, there is a layer with a thickness of $400 \mathrm{~m}$ with a uniform velocity layer of a very stiff soil or rock. The total depth to the bedrock is about $600 \mathrm{~m}$.

\section{Estimated Profile at CMA ("Marianistas" School)}

This place is located in the Bellavista district that belongs to the Callao Province. It is on the alluvial deposit that covers most of the central area of Lima city. Contrary to the soils in central Lima, the soils forming this district are fine. These are clays of $15 \mathrm{~m}$ thickness that were deposited by the Rimac River during the Holocene epoch when the river sedimentation power had decreased (Huaman et al 1991). The soil conformation around CMA consists of soft and stiff organic clays of high plasticity, high humidity of about $10 \mathrm{~m}$ depth. Underlying these materials there are fine soils of large depths such as clays of low and high plasticity, organic clays, and semi-dense silts until the alluvial gravel characteristic of Central Lima is found (Cismid 2005).

The estimated shear-wave velocity profile presented in Fig. 8 (g) shows a soft soil layer that is very shallow and may account for the organic soils described above. The next layer is of about $150 \mathrm{~m}$, with a velocity characteristic of very stiff soils. It is noticeable that from $200 \mathrm{~m}$ down the layers show an increasing velocity and the thickness of these layers is very random. However, the depth to the bedrock can be regarded as about $800 \mathrm{~m}$.

\section{Estimated Profile at CSM (CISMID, UNI)}

CISMID is a Research Center that belongs to the National University of Engineering. It is located in the alluvial deposit that covers most of the area of Lima city, and near the formation Puente Inga, which consists of igneous rocks. Due to the short distance to the hills the soils found here are stiff gravels at few meters depth.

The estimated shear-wave velocity profile is presented in Fig. 8 (h), it consists of a layer with a thickness of about $20 \mathrm{~m}$ in which the velocities are characteristic of very stiff gravel. At this depth the velocity shows a sudden increase which may account for the presence of weathered rock, this increase in velocities continues until it reaches the bedrock at approximately $100 \mathrm{~m}$ depth.

It is worth pointing out that profile at this place is the more rigid and shallow among other profiles estimated in this study; therefore, it can be regarded as a reference site for future amplification analysis. 

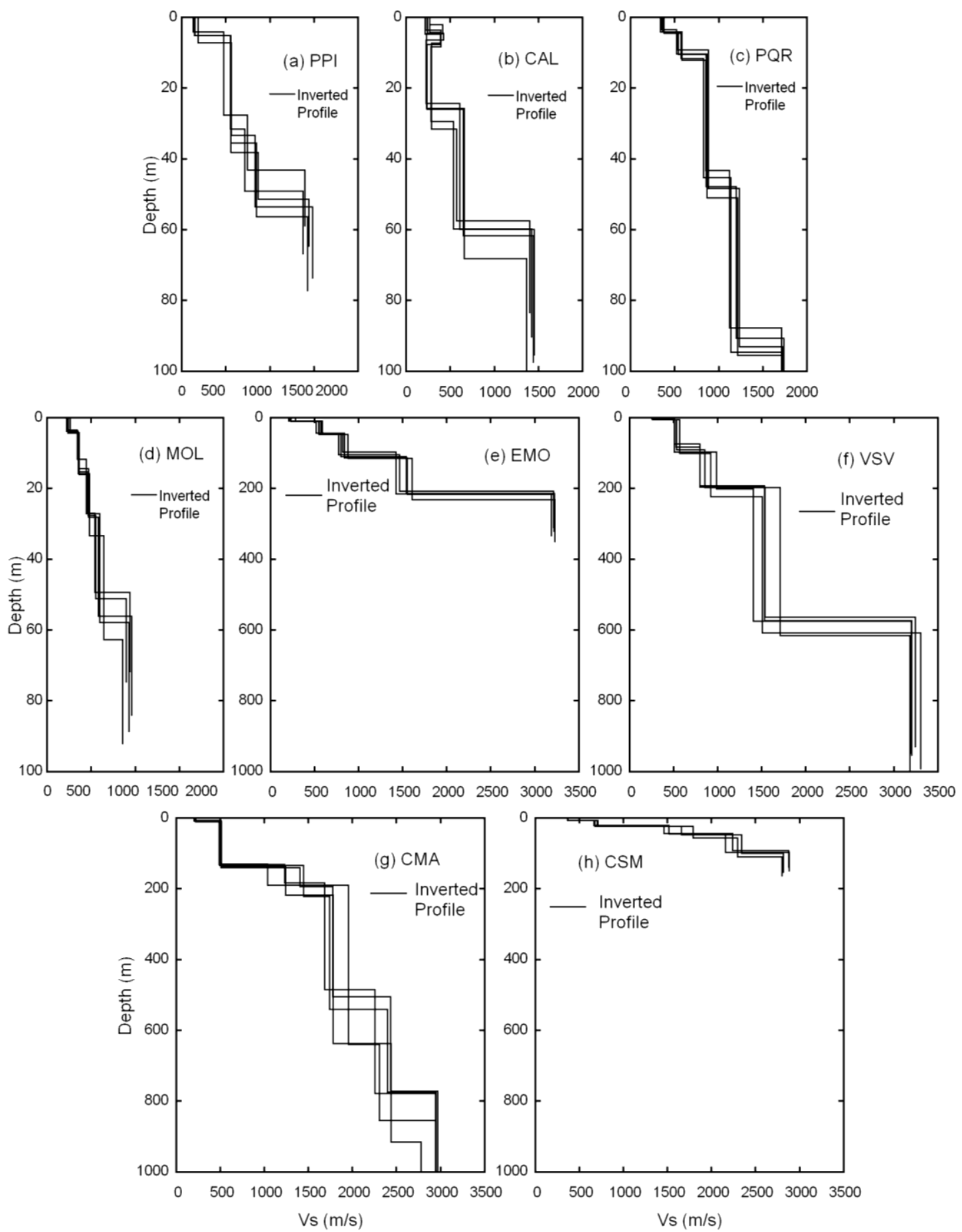

Fig. 8 Estimated shear-wave velocity profiles

\section{SITE EFFECTS}

\section{One-dimensional Ground Response Analysis}

One-dimensional ground response analyses are based on the assumption that all boundaries are horizontal and that the response of a soil deposit is predominantly caused by $\mathrm{SH}$ - waves propagating vertically from the underlying bedrock. For one-dimensional ground response analysis, the soil and bedrock surface are assumed to extend infinitely in the horizontal direction (Kramer, 1996). 

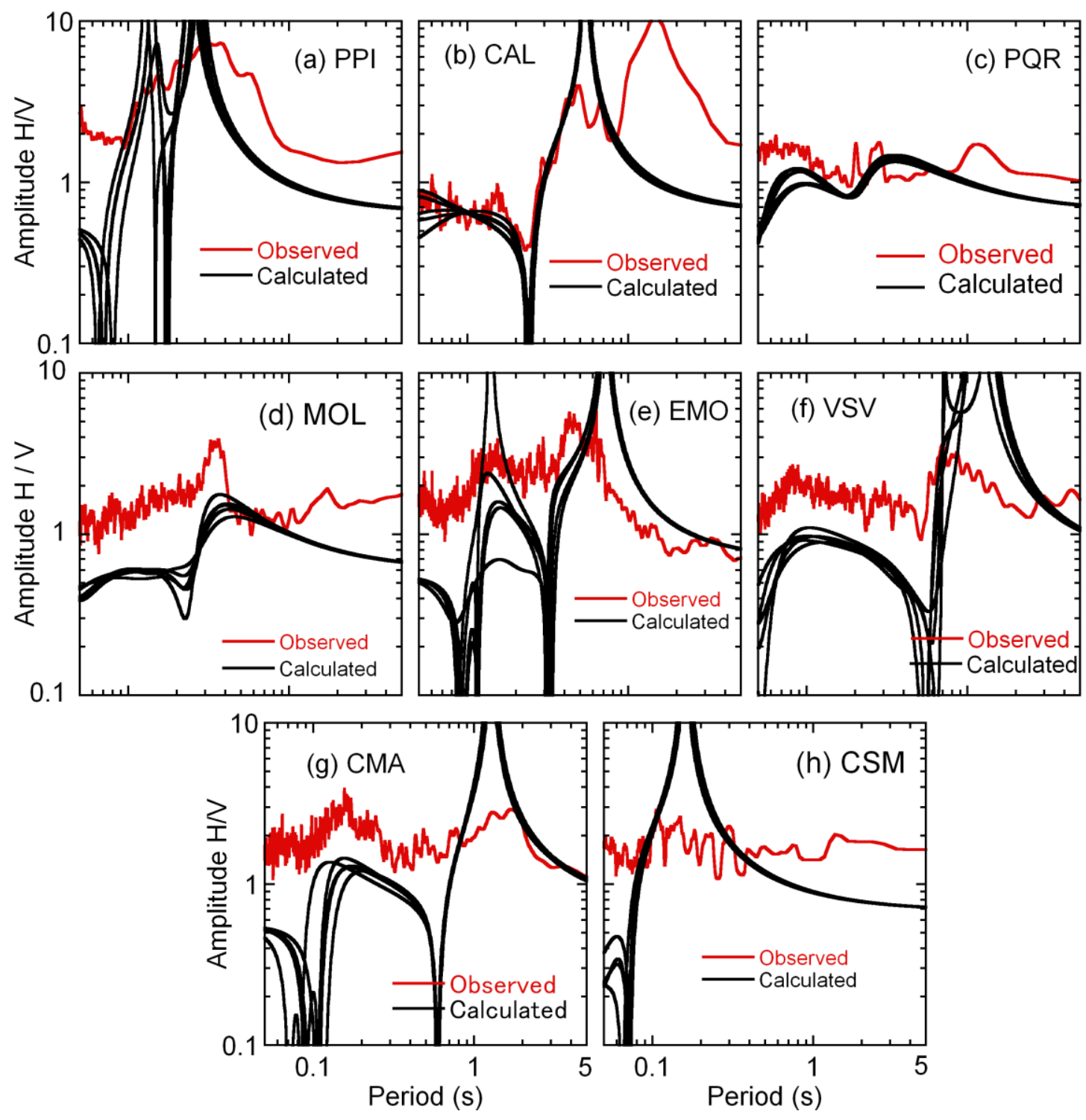

Fig. 9 Observed and Calculated H/V Spectra

\section{Linear Approach}

The key to the linear approach is the evaluation of transfer functions. The transfer functions can be used to express various response parameters, such as displacements, velocities or accelerations. Because it relies on the principle of superposition, this approach is limited to the analysis of linear systems. In this study we have used the one-dimensional linear approach to calculate the transfer functions because the area consisting of alluvial gravel deposits covers most of Lima.

\section{Amplification Factors}

For the calculation of the transfer function we have used the average of the five shear-wave velocity profiles estimated at each site and a damping factor of $2 \%$. CAL profile was completed until the bedrock taking as a reference the CMA profile because of their relative proximity. In Fig. 10 the extended profile and the $\mathrm{H} / \mathrm{V}$ spectrum of this profile are shown. It is important to note that by the extension of the profile a second peak in the calculated $\mathrm{H} / \mathrm{V}$ spectrum for a period of about 1.3 seconds is forming, although it is not as sharp as the peak in the observed $\mathrm{H} / \mathrm{V}$ spectrum. 

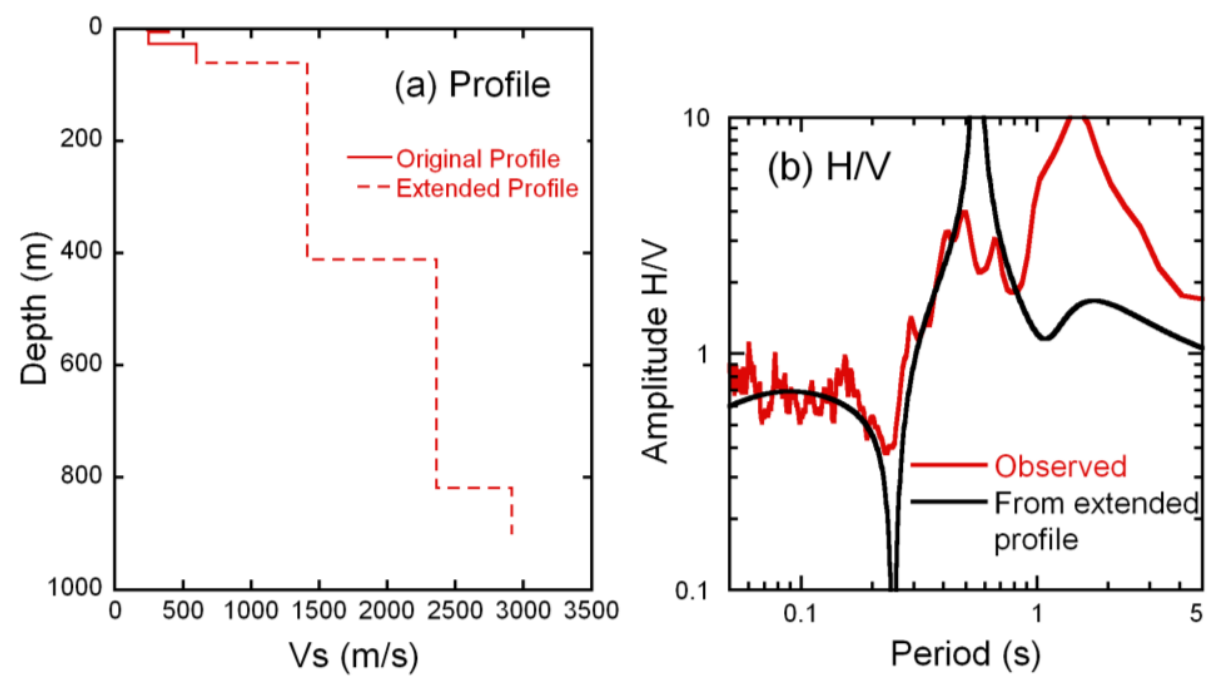

Fig. 10 Completed Shear-wave Velocity Profile and H/V at CAL

In Fig. 11 the calculated transfer functions are shown. PQR and MOL show a small amplification factor for a period of about three seconds. According to the soil classification, these places consist of alluvial gravel deposits. PPI and CSM are also over the alluvial deposit of Lima; however, they show a larger amplification for periods between 0.1 and 0.2 seconds, the large amplification can be produced by the large contrast of the first layers of the soil velocity profiles. At CAL the largest amplification is given for a period of approximately 0.5 seconds. It is important to note that the transfer function at EMO shows more than one large peak. Large amplifications at these places are expected since the soil deposits in both areas are soft (Cismid 2005), and historically large ground motions have been reported during important earthquakes (Espinoza et al 1977).

Finally, at VSV and CMA, the amplification is large for long periods of about 0.8 and 1.0 second respectively. Transfer function at CMA shows that there will be two periods for which the amplification will be very large (Fig.11 (g)).

\section{Site effects from CAL and CSM records}

CAL and CSM are stations that belong to the Cismid seismometer network as can be observed in Fig. 2. Transfer functions were calculated at these places (Fig. 11(b) and (h)) as it was explained in the previous section; and we will compare the characteristics of these transfer functions with the ground motion observed in CAL and CSM.

We have not used the seismic records from the new seismometers including CSM because large earthquakes have not been recorded yet there, and the small earthquakes recorded do not have enough power for the analysis in the long-period range.

In order to observe the vibration characteristics we have used three seismic records that were measured during the earthquakes of March $2^{\text {nd }} 2005$ at 08:48, March $29^{\text {th }} 2008$ at 01:40 and 07:51. Table 4 shows the characteristics of these earthquakes. From this table it is noted that the hypocentral distances are sufficiently larger than $13 \mathrm{~km}$ which is the distance between CAL and CSM station. This fact is enough to suppose that the source properties and the propagation path characteristics of the waves arriving at CAL and CSM, are almost the same. Figs. 12 (a), (b) and (c) show the Fourier Spectra at CAL station, and Figs. 12(d), (e) and (f) at CSM station. At both places site effects were identified; in the case of CSM, site effects are occurring at the period about 0.15 seconds. At CAL the site effects are occurring at about 0.15 and 0.5 seconds. These results are coherent with the transfer functions at CAL and CSM (Fig. 11(b) and 10(h)). 

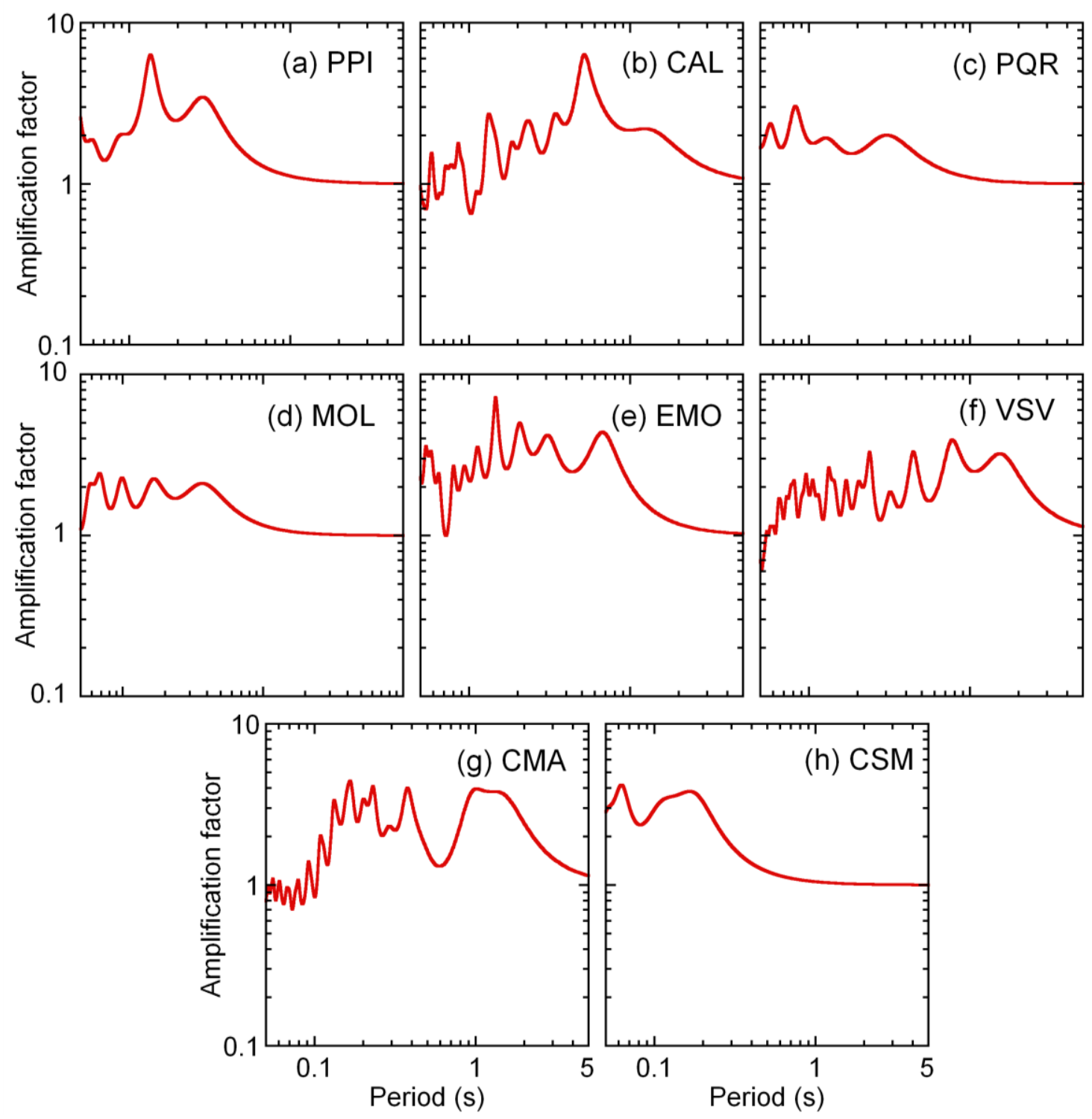

(e) EMO

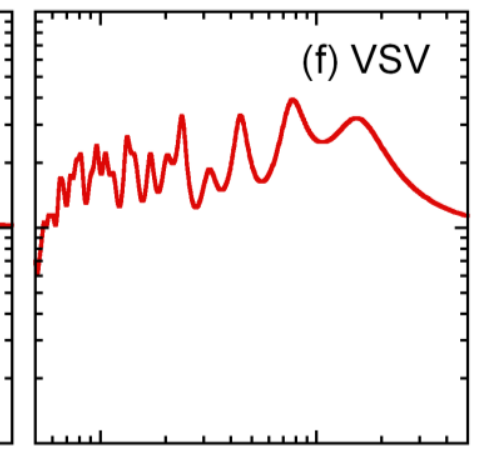

Fig. 11 Transfer functions from estimated profiles

With the purpose to compare site effects from seismic records and from the inverted profiles, the observed and computed spectrum ratios were calculated as shown in Fig. 13. The observed spectrum ratio is the relation between the Fourier spectra of the ground acceleration in the transversal component at CAL and CSM. On the other hand, the computed spectrum ratio is the relation between the transfer function at CAL and CSM, as it was explained earlier, the transfer functions were calculated from the inverted profiles. From Fig. 13 we can observe that there is a good agreement between the observed and computed spectrum ratios for the peak period between 0.5 and 0.6 seconds, this fact verifies that at CAL a large amplification will occur at that range of periods. On the other hand, the maximum peak period of the observed spectra is clearly seen at about 1.2 seconds; however, in the computed spectra the peak at this period shows a very low amplification, meaning that the extended profile in Fig. 10 (a) needs to be examined in more detail. Regarding the site-effect at CSM, the minimum peak occurring at a period of about 0.1 seconds reflects the site effect at CSM site. 
Table 4 Characteristics of the earthquakes used in the amplification studies.

\begin{tabular}{|c|c|c|c|c|c|c|}
\hline Date & $\begin{array}{c}\text { Local } \\
\text { Time }\end{array}$ & $\begin{array}{c}\text { Longitude } \\
(\mathrm{deg} .)\end{array}$ & $\begin{array}{c}\text { Latitude } \\
(\mathrm{deg} .)\end{array}$ & $\begin{array}{c}\text { Magnitude } \\
\left(M_{W}\right)\end{array}$ & $\begin{array}{c}\text { Hypocentral } \\
\text { Distance to } \\
\text { CSM }(\mathrm{km})\end{array}$ & $\begin{array}{c}\text { Focal } \\
\text { Depth } \\
(\mathrm{km})\end{array}$ \\
\hline $2005 / 03 / 02$ & $08: 48$ & -76.14 & -11.86 & 6.0 & 160 & 124 \\
\hline $2008 / 03 / 29$ & $01: 40$ & -77.73 & -12.17 & 4.6 & 90 & 48 \\
\hline $2008 / 03 / 29$ & $07: 51$ & -77.25 & -12.25 & 5.6 & 61 & 51 \\
\hline
\end{tabular}
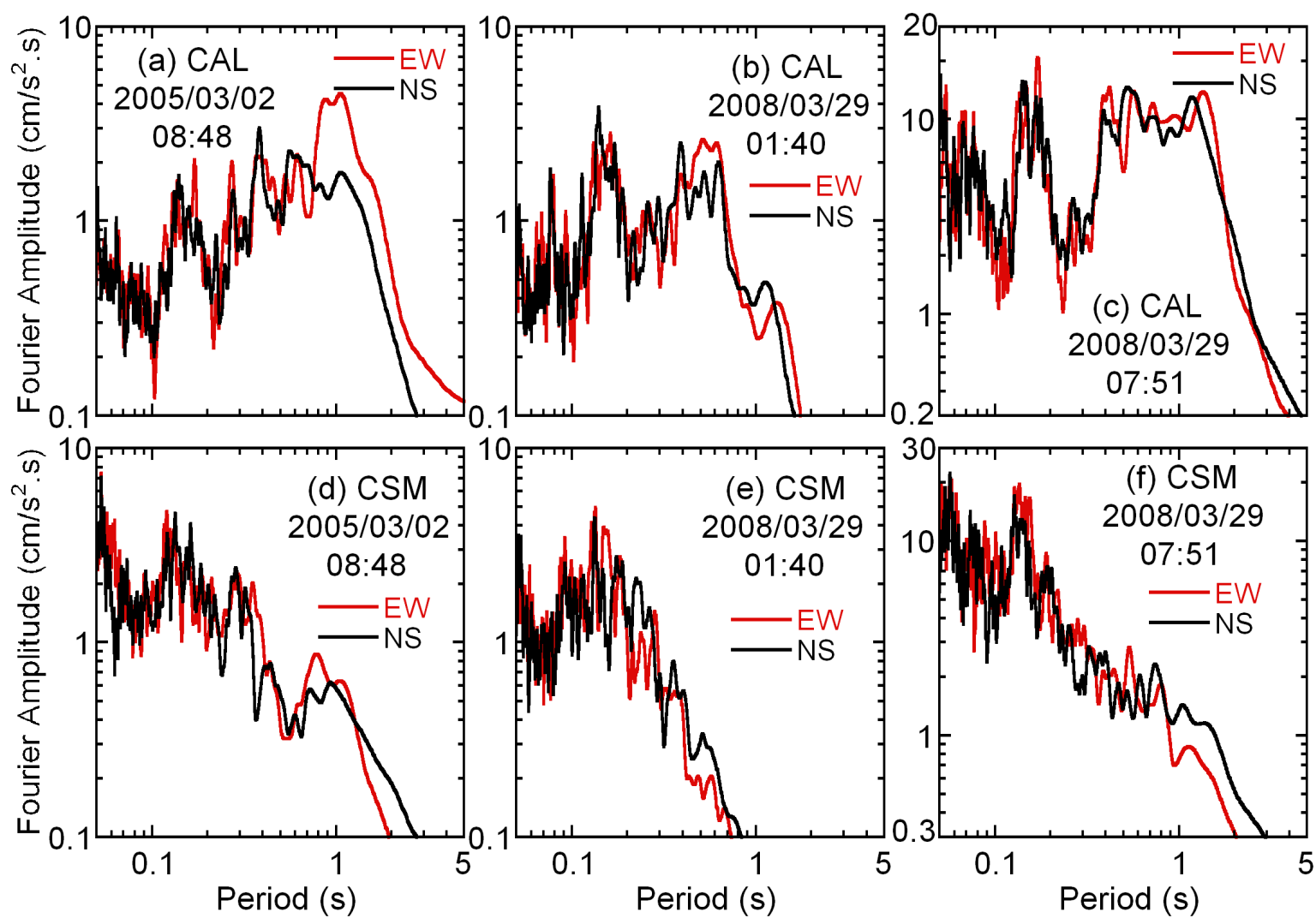

Fig. 12 Fourier spectra for the East-west (EW) and North-South (NS) components of three seismic events recorded in CAL and CSM stations from the Cismid seismometer network.

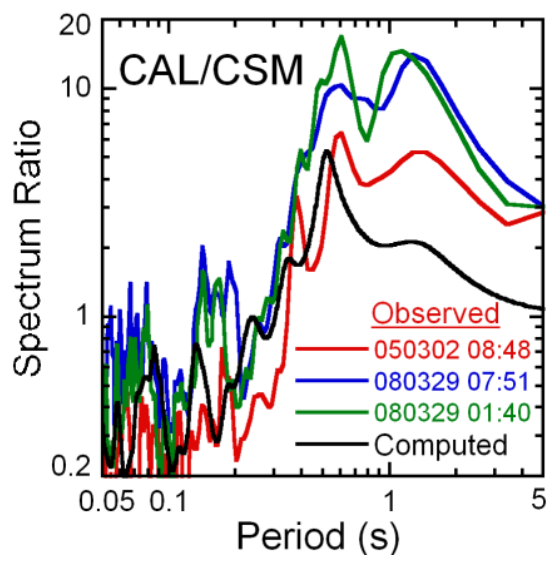

Fig. 13 Observed and computed spectrum ratio between CAL and CSM stations. 


\section{CONCLUSIONS}

We have evaluated the amplification factors at eight places in Lima. In the process we have obtained the next conclusions.

1. We have obtained a broad picture of the deep soil structure in Lima, where no information was available up to now.

2. A range of periods where the power of the signal is low was identified; it is from about 0.5 to 1.5 seconds. In this range the dispersion curve is not continuous.

3. Amplification factors at VSV, EMO, CAL and CMA were the largest; it is coherent with the soil types in these places that are sands or clays, and with the peak periods of the H/V spectra.

4. We have confirmed the site-effects on seismic records by using the profiles we estimated from array measurements.

\section{ACKNOWLEDGMENT}

The nc-CCA analysis in this study was carried out using the software BIDO version 2.0 downloaded from the website: http://staff.aist.go.jp/ikuo-chou. We would like to thank the software creator's team for providing the free usage of the software.

We are grateful to the assistant researchers of Cismid who helped us to conduct the array measurements and to install the seismometers. In particular, we wish to thank Rocio Uriarte and Carlos Gonzales for their cooperation in drawing the images and processing the data.

Finally, we would like to express our sincere gratitude to the referees for their valuable opinions and suggestions.

\section{REFERENCES}

Aki, K. (1957). "Space and time spectra of stationary stochastic waves, with special reference to Microtremors". Bull. Earthq. Res. Inst., Vol. 35, 415-456.

Capon, J. (1969). "High-resolution frequency-wavenumber spectrum analysis." Proc. IEEE, Vol. 57, No. 8, 1408-1418.

Cismid (2005). "Study of the Vulnerability and Seismic Risk in 42 districts of Lima and Callao", Japan - Peru Center for Earthquake Engineering Reseearch and Disaster Mitigation, National University of Engineering, Lima, Peru. (in spanish)

Cismid (2010a). "Seismic Microzonation of Villa El Salvador", Japan - Peru Center for Earthquake Engineering Reseearch and Disaster Mitigation, National University of Engineering, Lima, Peru. (in spanish)

Cismid (2010b). "Seismic Microzonation of the La Molina", Japan - Peru Center for Earthquake Engineering Reseearch and Disaster Mitigation, National University of Engineering, Lima, Peru. (in spanish)

Cismid (2010c). "Seismic Microzonation of Chorrillos", Japan - Peru Center for Earthquake Engineering Reseearch and Disaster Mitigation, National University of Engineering, Lima, Peru. (in spanish)

Cismid (2010d). "Seismic Microzonation of Puente Piedra", Japan - Peru Center for Earthquake Engineering Reseearch and Disaster Mitigation, National University of Engineering, Lima, Peru. (in spanish)

Cismid (2010e). "Seismic Microzonation of Comas", Japan - Peru Center for Earthquake Engineering Reseearch and Disaster Mitigation, National University of Engineering, Lima, Peru. (in spanish) 
Cismid (2010f). "Seismic Microzonation of San Juan de Lurigancho", Japan - Peru Center for Earthquake Engineering Reseearch and Disaster Mitigation, National University of Engineering, Lima, Peru. (in spanish)

Cho, I., Tada, T. and Shinozaki, Y. (2004). "A new method to determine phase velocities of Rayleigh waves from microseisms." Geophysics Vol. 69, 1535-1551.

Tada, T., Cho, I., and Shinozaki, Y. (2007). "Beyond the SPAC Method: Exploiting the Wealth of Circular-Array Methods for Microtremor Exploration." Bulletin of the Seismological Society of America, Vol.97, no. 6, 2080-2095.

Tada, T., Cho, I., and Shinozaki, Y. (2010). "Analysis of Love-wave components in microtremors." Joint Conference Proceedings, 7th International Conference on Urban Earthquake Engineering (7CUEE) \& 5th International Conference on Earthquake Engineering (5ICEE), Center for Urban Earthquake Engineering, Tokyo Institute of Technology. 115-124. (http://www.cuee.titech.ac.jp /Japanese/Publications/Doc/conference_7th.pdf).

Espinosa, A. F. (1977). "The Lima Earthquake of October 3, 1974: Intensity Distribution." Bulletin of the Seismological Society of America, Vol.67, 1429-1439.

Goldberg, D. E. (1989). Genetic algorithms in Search, Optimization, and Machine Learning, Addison-Wesley Publishing Company Inc.

Huaman, C. E. (1991). "Seismic Microzonation of La Punta and El Callao", Thesis, Faculty of Civil Engineering, National University of Engineering, Lima, Peru.

Husid, L. R.. (1969), “Características de terremotos - análisis general”. Revista del IDIEM 8, 21-42, Santiago, Chile. (in spanish)

INGEMMET (1992). "Geology of the Quadrangle Maps of Lima, Lurín, Chancay and Chosica", Instituto Geológico, Minero y Metalúrgico, Boletín N43 (in spanish)

Karakouzian, M. (1997). "Geology of Lima, Peru”. Environmental \& Engineering Geoscience, Vol. 3, 55-88.

Kitsunezaki, C., et al. (1990). "Estimation of P- and S- Wave Velocities in Deep Soil Deposits for Evaluating Ground Vibrations in Earthquake", Journal of Japan Society for Natural Disaster Science, Vol. 9, no.3, 1-17.

Kramer, S. L. (1996). Geotechnical Earthquake Engineering, Publ. Prentice Hall, USA.

Le Roux, J. P., Tavares Correa, C., Alayza, F. (2000). "Sedimentology of the Rímac-Chillón alluvial fan at Lima, Peru, as related to Plio-Pleistocene sea-level changes, glacial cycles and tectonics". Journal of South American Earth Sciences. Vol. 13, 499-510.

Martínez, A., and Porturas, F.(1975). "Geotechnical Maps for Lima-Peru". Reunión Andina de Seguridad Sísmica, Pontificia Universidad Católica del Perú. (in spanish)

Park, C. B., Miller, R. D., Xia, J. (1999). "Multi-channel analysis of surface waves (MASW)": Geophysics, Vol. 64, no. 3, 800-808.

Tokimatsu, K. (1992). "Effects of Multiple Modes on Rayleigh Wave Dispersion Characteristics", Journal of Geotechnical \& Geoenvironmental Engineering, Vol. 118, No10, 1529-1543.

Tokimatsu, K. (1995). "Geotechnical Site Characterization Using Surface Waves", Proc., First Int. Conf. on Earthquake Geotechnical Engineering, 1333-1368. 